\title{
Piloting the Use of Smartphone Applications as Learning Resources in Clinical Nursing Education
}

\author{
Khraim, Fadi ${ }^{1}$, Sandra Small PhD RN ${ }^{2}$, Daphne Crane MDE ${ }^{3}$, Claudine Morgan BN RN \\ ${ }^{1}$ Assistant Professor, Memorial University, School of Nursing, 300 Prince Philip Drive \\ ${ }^{2}$ Associate Professor, Memorial University, School of Nursing \\ ${ }^{3}$ Senior Instructional Designer, Distance Education, Learning and Teaching Support, Memorial University \\ ${ }^{4}$ Clinical Coordinator, Memorial University, School of Nursing
}

\begin{abstract}
:
Smartphones are becoming ubiquitous with abundantly available nursing learning applications. Thirteen nursing students participated in a study to explore the benefits and barriers of using smart phones to access nursing learning resources in clinical practice. Voice- and data-enabled smart phones were provided to participants. A mix-methods research approach was used with pre- and post-surveys. Prior to the study, participants' experience with smart phone technology ranged from no experience at all to having extensive experience. One key finding is that students did not feel comfortable using smart phones in the clinical setting. Therefore, smart phones received little use as a learning resource. Unprofessional appearance and the time needed to learn the technology were the main deterrent of smart phone use. The results of this investigation add to the growing body of research that discusses adoption of smart phone technology in nursing education.
\end{abstract}

Keywords:Smartphone, Nursing Learning Applications, Nursing Education, Nursing Practice, Smart Teaching Strategies.

\section{INTRODUCTION}

Adoption of smart electronic technologies such as digital hand-held mobile devices among health care professionals is on the rise[1,2]. The use of personal digital assistants (PDAs) has long been at the core of innovation in health care and nursing education[3-5]. However, as technology continues to evolve these PDAs became smarter with greater capabilities such as larger storage capacities, faster processors, user-friendly interfaces, cellular phone abilities, and most importantly their ability to connect to the internet via wireless means[6,7].

Nursing education depends greatly on smart electronic technologies [8,9]. Smart technologies such ascomputerized interactive learning modules and virtual or distance education classrooms are replacing dated over-head projection lectures and traditional classroom environment. The use of web-enabled mobile communication devices such as smartphonesinforms this leap in using technology in nursing education. These devices provide a venue for nursing students to access and utilize the latest health care information[2,10]. These devices also provide convenience in communicating with course instructors that allows for timely feedback to students and a balanced learning experience [8]. Health care is one of the fastest sectors on the uptake of mobile technologies. Nurses, doctors, therapists and other health care providers are using mobile devices to collaborate with others, carry out research, and look up and record information[6]. Health care students, including nursing students, need to gain experience with appropriate use of mobile technology in health care settings.

Despite the plethora of research on the use of PDAs in health care and nursing education[10], we know little about the use of smartphones in clinical nursing education. This wasa pilot study to investigate the benefits and barriers of using smartphone by nursing students enrolled in a clinical practice course.The outcome of this investigation will inform the use of smartphone use in an educational setting outside a formal (physical or virtual) classroom.

\section{STUdY METHODS}

This was anexploratory descriptive mixed methods approach study.

${ }^{1}$ Corresponding Author: fkhraim@mun.ca 


\subsection{Sample and Settings}

Twenty seven nursing students in the fast-track Bachelor of Nursing (FBN) program at one school of nursing in the Atlantic Canada were recruited for the study. In addition to completing nursing prerequisites (e.g. biology, biochemistry, and statistics), students in the FBN program are accepted in the program if they have completed at least 2 years of formal university education or have earned a bachelor degree in an another program and have earned a GPA of 3.0 or higher. The FBN students usually complete their program of study over six consecutive semesters (about 2 years). The invitedstudents were registered for a consolidated clinical practicum course. The course involves 40 hours a week of clinical practice for ten weeks and takes place just prior to graduation from the program. In this clinical practicum, each student is assigned to work with a registered nurse preceptor. The student gradually assumes a more independent role working collaboratively with other health care personnel in the unit. The school of nursing clinical professor typically oversee the clinical experience in this course communicating back and forth with students and their perspective clinical preceptors. The usual clinical placement areas for this course are acute care nursing units including medical, surgical, mental health, women's health, paediatric, and critical care settings.

The study was approved by the University ethics committee and informed written consent was obtained from the participants. Participants were provided with free-of-charge smartphones (Blackberry Bold 9700 TM) that were voice- and data-enabled (Bell®). The Blackberry Bold 9700 smartphones have 256RAM memory, 2G media card (with camera, video, and media player). Using these devices participants were able to access web-browser and other communication tools such as phone, email, text messaging, instant messaging and social networking.

The Skyscape Nursing Constellation Plus ${ }^{\mathrm{TM}}$ set of recourses were pre-installed on the smartphones[11]. This set of nursing recourses included Davis's Drug Guide $₫$, Taber's Medical Dictionary $₫$, Diseases and Disorders $₫$, Davis's Laboratory and Diagnostic Tests $®$, MEDLINE $®$ Journals, RNotes ${ }^{\circledR}$, Nurse's Clinical Pocket Guide $®$, Nurses' Handbook of Health Assessment ${ }^{\circledR}$, and Nurse's Pocket Guide Diagnoses, Prioritized Interventions and Rationales®. Participants were offered instructional support on the use of the smartphone and the applications both prior to and during the study using web-based information, face-to-face instruction, and a telephone helpline. Moreover, the research team provided the participants with support letters regarding the study to share with their clinical preceptors.

\subsection{Data Collection}

Participants were asked to complete pre- and post- web-based surveys that were specially developed to collect data on benefits and barriers of using smartphones to access nursing resources, such as guides or manuals for drugs, diseases, and nursing care plans. The surveys included close-ended questions that limited the respondents to a specific answer such as Yes/No response options (example: "If you had a choice, would you use a smartphone in your clinical practice?"), and open-ended questions whereby participants were asked to comment on their expectations concerning smart phone technology prior to the study and their experience with it during the study (example: "Please explain why the smartphone provided to you was useful or not useful. Please be as detailed as you can.").

\subsection{Data Analysis}

Data collected were analysed using descriptive statistics for the quantitative data and content analysis for the qualitative data to identify common themes. The researchers were not involved in teaching the students at the time of the study.

\section{RESULTS}

All students in the clinical course (27 students) were invited to participate in the study. Only 13students completed the study out of 14 who originally consented to participate and completed the pre-survey. This is because one participant dropped out of the study prior to completing the study stating being busy and overwhelmed with the clinical course experience and having no time to participate effectively. Table 1 illustrates the demographics of participants who consented to participate $(\mathrm{n}=14)$. Some of the students who did not consent feared that participation in the study may require them to spend time to learn devices and the applications provided.

Table1. Demographics of Study Participants $(n=14)$

\begin{tabular}{|l|l|l|}
\hline \multicolumn{2}{|l|}{ Demographics } & Number (\%) \\
\hline Sex & Male & $1(7 \%)$ \\
& Female & $13(93 \%)$ \\
\hline
\end{tabular}


American Research Journal of Nursing, Volume 1, Issue 3, 2015

ISSN 2379-2922

\begin{tabular}{|l|l|l|}
\hline Clinical Practice Location & In-province & $11(79 \%)$ \\
& Out-of-province & $3(21 \%)$ \\
\hline Clinical Placements & Pediatrics & $1(7 \%)$ \\
& Critical Care & $3(21 \%)$ \\
& Emergency Room & $1(7 \%)$ \\
& Mental Health & $1(7 \%)$ \\
& Medical/Surgical & $8(57 \%)$ \\
\hline
\end{tabular}

Eight participants (57\%) owned a smartphone. Those who owned a smartphone prior to the study used it for communication (phoning, emailing, texting, social media), learning (looking up medications, lab values, nursing intervention, accessing courses material, etc.), or other applications (e.g. calculator, weather, maps), see Figure 1. The pre-survey revealed that the main concern of participants regarding using a smart phone in their clinical practice was the lack of familiarity with institutional policies $(n=6)$, complexity of the device $(n=5)$, processing speed $(n=$ $2)$, or small screen size $(n=1)$.

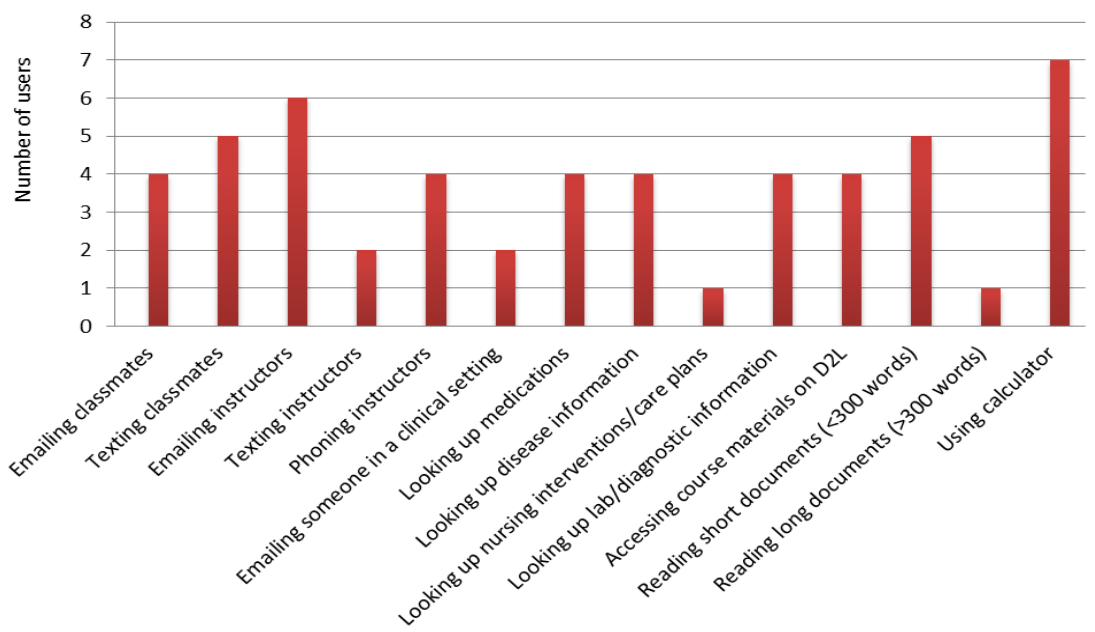

Fig1. Types of smartphone use among participants prior to the study $(n=8)$

Table2. Barriers of using smartphones as quoted by participant

\begin{tabular}{|c|c|}
\hline Barriers & Example Participant Quotes \\
\hline \multirow[t]{3}{*}{$\begin{array}{l}\text { "Unprofessional" } \\
\text { Appearance in the } \\
\text { Clinical Setting }\end{array}$} & $\begin{array}{l}\checkmark \text { "I also know that there are some people who do use personal hand-held devices in } \\
\text { the clinical setting on a regular basis and I must say that in general I have never } \\
\text { approved of it. I think adding technology to that setting will just take away from } \\
\text { patient contact. You do not need another piece of equipment between you and the } \\
\text { patient." }\end{array}$ \\
\hline & $\begin{array}{l}\checkmark \quad \text { "IIt] didn't feel appropriate to use it on the unit, as it looks distasteful to see health } \\
\text { professionals on their phones while at work, so I really cannot say that I used it to } \\
\text { its full helping potential." }\end{array}$ \\
\hline & $\begin{array}{l}\checkmark \text { "Cell phones at work have a bad connotation with patients, families, and staff } \\
\text { alike. I didn't like feeling that I had to sneak off the unit to look something up or to } \\
\text { consult the [B]lackberry." }\end{array}$ \\
\hline \multirow[t]{2}{*}{$\begin{array}{l}\text { Device and Software } \\
\text { not "User Friendly" }\end{array}$} & $\begin{array}{l}\checkmark \text { "The [B]lackberry was difficult to use and the applications often took [too] long to } \\
\text { navigate to find information. I found myself becoming frustrated with the } \\
\text { applications and just using the computer or medication book to look up } \\
\text { information." }\end{array}$ \\
\hline & $\begin{array}{l}\checkmark \text { "I tried using it in clinical but I found the software to be very "clunky", having used } \\
\text { previous handheld devices with other software I found the software in this study to } \\
\text { not be very student friendly. I found it hard to navigate between pages, hard to }\end{array}$ \\
\hline
\end{tabular}




\begin{tabular}{|l|l|l|}
\hline & $\begin{array}{l}\text { search for items, and difficult to learn. After a little while I found I resorted back to } \\
\text { using the software I was using previously." }\end{array}$ \\
$\checkmark$ & $\begin{array}{l}\text { "Plus there were computers everywhere with faster internet access and they were } \\
\text { much easier to read from }\end{array}$ \\
\hline $\begin{array}{l}\text { Lack of "Time to } \\
\text { Smartphone / } \\
\text { Applications }\end{array}$ & $\checkmark$ & $\begin{array}{l}\text { "I did not use it unfortunately. I found I didn't have any time to learn how to use it } \\
\text { or the applications." } \\
\text { "In theory the smartphone is a fantastic device; unfortunately, I personally feel } \\
\text { uncomfortable with the newer technology as it requires time and with this clinical } \\
\text { course time was always lacking." }\end{array}$ \\
& $\checkmark \begin{array}{l}\text { "If the choice was mine I would take the time to use it but the floor I was on was } \\
\text { busy and there wasn't a good place to take out the phone to access the information } \\
\text { while on the floor. It was more time efficient to use internet resources." }\end{array}$
\end{tabular}

The smartphones and the application were underutilized by a majority of the participants who completed the study. Twelve participants $(92 \%)$ reported that they never used the smartphone and its application to its potential, and 10 (77\%) did not find the provided smartphone useful for their clinical experience. Students reported various barriers that impeded using the smartphones. Being perceived as "unprofessional", lack of ease of the smartphone, and lack of time to learn about the smartphone and the provided applications were the most common stated barriers. Table 2 provides a summary of the barriers of using smartphones as quoted by participant. Moreover, Instructional support available for the students was not utilized by any participant.

With the exception of thedrug index application that was used daily by $54 \%$ of the participants, other applications (emailing, texting, web browsing, and accessing course material and other clinical learning resources) were either never used or used only occasionally during study, see Figure 2.Generally, participants reported that they often reverted to using conventional methods (e.g., using personal computers) to communicate with their clinical instructor, to access course material, or access clinical learning resources. Participants who had a favourable opinion on using smartphones in the clinical setting reported the following reasons:

$>$ Useful for accessing clinical resources (e.g. drug application)

$>$ Ability to communicate with fellow students and course instructor

$>$ Access to the internet

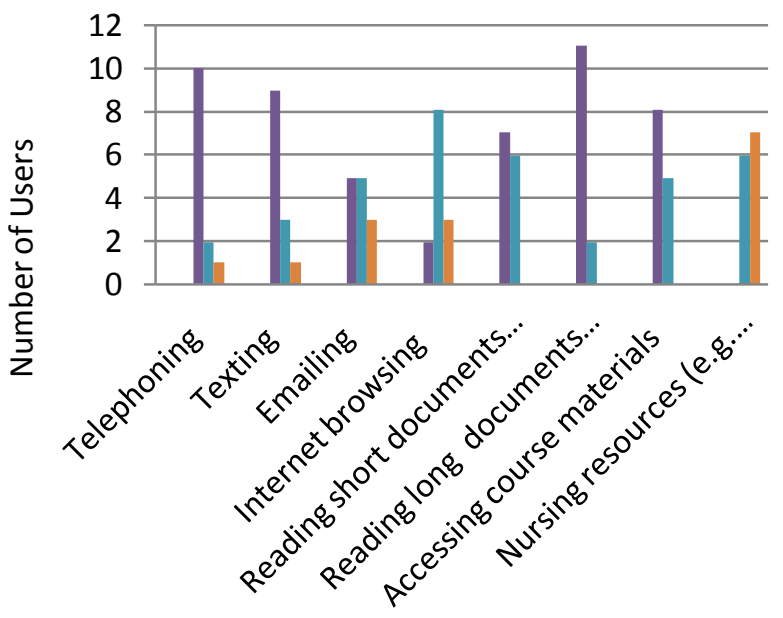

Fig2. Participants use of smartphone features during the study $(n=13)$.

\section{DISCUSSION}

Smartphones are handheld web-enabled mobile communication devices that potentially allow nursing students to access and utilize up-to-date clinical resources and evidence based information. They also provide a platform for instant mobile communication between students and their instructors. This pilot study presents the use of 
smartphone-based nursing learning applications by nursing students enrolled in a clinical course at a Canadian university. The results of this study inform the use of smartphones and their applications as learning tools for nursing students in clinical practice.

The study revealed that $57 \%$ of study participants owned smart phones at the time of recruitment to the study. This proportion is consistent with other reports that measured ownership of smartphones among adult Canadians at the time of conducting the study $[12,13]$.

Prior to participating in the study, lack of familiarity with institutional policies on the use of smart phones within the clinical settings was a main concern by a majority of participants. This concern may be justified by fear breaching patient confidentiality or professional standards of clinical nursing practice, fear that the smartphone signal may cause interference with other equipment at the clinical setting or fear that the device might aid in transmission of microorganisms [10].

Thirty six per cent of study participants expressed their concern with the complexity of smartphones and the time needed to learn its use even before using the devices provided in the study. Similarly, lack of perceived userfriendliness was identified as a barrier to smartphone use during the study. Concernsabout the complexity and userfriendliness of the device along with the lack of familiarity with institutional policies for smartphone use explain the participants' limited use of the smartphones and the learning applications. These concerns also explain why participants often reverted to using conventional methods to obtain information they needed or to communicate with their instructors.

This study further revealed that a large percentage of participants (77\%) did not find the smartphone helpful with their clinical experience. This finding is in contrast with results of studies of other students, including nurse practitioner students and medical students. Robinson et al. (2013) reported that the majority of medical student at a university in the UK believed that smartphones are useful [14]and Wyatt et al. (2010) reported similar results with nurse practitioner students in the USA[15].

The barriers that are reported in Table 2 further validate the reasons for lack of using the smartphones as learning tool in the clinical setting. However, these barriers are not unique to this study as suggested in earlier literature. Other researchers indicated that the level of smartphone interface simplicity and how easy it is to learn how to use the smartphone are among the common challenges for adopting this technology in nursing education $[10,16]$. Furthermore, concern about "unprofessional" appearance when using smartphones in the clinical practice has been identified in other studies. These reports indicated that associating the use of smartphone in clinical setting with lack of "professional" appearance is main deterrent to using the smartphone[14,17,18].

The course in which the study was conducted was the last course in the baccalaureate program for these students. It was a demanding clinical practice course in which the students were expected to demonstrate proficiency and competency in nursing practice. Therefore, this potentially overwhelmed the participants and hindered them from learning the different functions of the smartphones which resulted in lack of effective use during the clinical experience.

On the other hand, participants who supported using smartphones in clinical nursing education reported some benefits to that. These benefit such as accessibility to clinical resources, internet, and ability to communicate with the instructors and other colleagues are also documented in earlier literature [10,16,17].

\section{CONCLUSION AND IMPLICATIONS}

Smartphones are telecommunication and computing devices that can access the internet allowing its user to look up and utilize up-to-date information. Therefore, smartphones hold significant potential for advancing nursing education. While the study was successful in identifying various barriers and benefits of using smartphones in clinical nursing education, some limitations existed. A small and unrepresentative sample size prohibits generalization of the results to other nursing students. Furthermore, the timing of the clinical course when the study was conducted (last course prior to completing the program) may have caused participants to be overwhelmed, thus limiting their participation in the study effectively. Future studies in this area of research would require taking such limitations in consideration.

Nonetheless, this study was able to provide a valuable perspective on using this technology in clinical nursing education. Policies related to appropriate use of smartphones at the clinical setting need to be easily accessible to 


\section{American Research Journal of Nursing, Volume 1, Issue 3, 2015}

ISSN 2379-2922

students so they are aware of what is acceptable use of this technology at the agency. This essentially would help alleviate the perceptions of "Unprofessional" appearance in the clinical setting for those who use smartphones.

Furthermore, in order to provide grounds for successful and beneficial use of this technology, user-friendly devices and adequate training time on effective use of it and its application will need to be provided. Assmartphones and applications were provided free-of-charge to participants in this study, further research is required to determine the influence of cost of purchasing smartphones and clinical applications has on its adoption. Furthermore, this study provided a short-term account of benefits and barriers of using smartphones in nursing education; hence, a longitudinal study that measures these variables across various clinical courses may be warranted.

\section{ACKNOWLEDGMENT}

Financial support for this study was provided by Distance Education and Learning Technologies, Memorial University of Newfoundland.

Conflict of Interest: The authors declare no conflict of interest.

\section{REFERENCES}

[1] Lindquist, M. A., Johansson, E. P., Petersson, I. G., Saveman, B., \& Nilsson, C. G. (2008). The use of the personal digital assistant (PDA) among personnel and students in health care: A review. J Med Internet Res, 10(4), e31. Retrieved from http://www.jmir.org/2008/4/e31/; http://dx.doi.org/10.2196/jmir.1038; http://www.ncbi.nlm.nih.gov/pubmed/18957381

[2] Mosa, A. S., Yoo, I., \& Sheets, L. (2012). A systematic review of healthcare applications for smart phones.BMC Medical Informatics and Decision Making, 12(1), 67.

[3] Clark, K., Colevins, H., \& Bond, D. (2009). Crossing the clinical chasm: From the backpack to the palm. Journal for Nurses in Professional Development, 25(2)Retrievedrom http://journals.lww.com/jnsdonline/Fulltext/2009/03000/Crossing_the_Clinical_Chasm_From_the_Backpack_to.17.aspx.

[4] Garritty, C., \& El Emam, K. (2006). Who's using PDAs? estimates of PDA use by health care providers: A systematic review of surveys. J Med Internet Res, 8(2), e7.

[5] McLeod, R. P., \& Mays, M. Z. (2008). Back to the future: Personal digital assistants in nursing education. Nursing Clinics of North America, 43(4), 583-59

[6] Boulos, M., Wheeler, S., Tavares, C., \& Jones, R. (2011). How smart phones are changing the face of mobile and participatory healthcare: An overview, with example from eCAALYX. BioMedical Engineering OnLine, 10(1), 24.

[7] Wikipedia. (2015). Smart phone .Retrieved November/1, 2014, from http://en.wikipedia.org/wiki/Smart phone .

[8] Baumgart, D. C. (2005). Personal digital assistants in health care: Experienced clinicians in the palm of your hand? The Lancet, 366(9492), 1210-1222.

[9] Luanrattana, R., Win, K., \& Fulcher, J. (2007). Use of personal digital assistants (PDAs) in medical education. 20th IEEE International Symposium on Computer-Based Medical Systems, 307-312.

[10] Phillippi, J. C., \& Wyatt, T. H. (2011). Smart phones in nursing education. Computers Informatics Nursing, 29(8), 449454.

[11] Skyscape.(2013) .Nursing constellation plus ${ }^{\mathrm{TM}}$. Retrieved May/29,2015,from http://www.skyscape.com/estore/productdetail.aspx?ProductId=2392

[12] eMarketer. (2014). Smart phones take the lead in Canada. Retrieved November/29, 2014, from http://www.emarketer.com/Article/Smart phones-Take-Lead-Canada/1009759

[13] Oliveira, M. (2013). Google study: Smart phone ownership way up, Canadians addicted to their phones. Retrieved July/29, 2014, from http://www.ctvnews.ca/sci-tech/google-study-smart phone -ownership-way-up-canadians-addicted-to-theirphones-1.1388185\#ixzz2dADOjvFA

[14] Robinson, T., Cronin, T., Ibrahim, H., Jinks, M., Molitor, T., Newman, J., \& Shapiro, J. (2013). Smart phone use and acceptability among clinical medical students: A questionnaire-based study. Journal of Medical Systems, 37(3), 1-7.

[15] Wyatt, T. H., Krauskopf, P. B., Gaylord, N. M., Ward, A., Huffstutler-Hawkins, S., \& Goodwin, L. (2010). Cooperative mlearning with nurse practitioner students.Nursing Education Perspectives, 31(2), 109-113.

[16] Lamarche, K., \& Park, C. (2012). The views of nurse practitioner students on the value of personal digital assistants in clinical practice.CJNI, 6(4).

[17] Davies, B. S., Rafique, J., Vincent, T. R., Fairclough, J., Packer, M. H., Vincent, R., \&Haq, I. (2012). Mobile medical education (MoMEd)-how mobile information resources contribute to learning for undergraduate clinical students-a mixed methods study.BMC Medical Education, 12(1), 1.

[18] Wu, R. C., Tzanetos, K., Morra, D., Quan, S., Lo, V., \& Wong, B. M. (2013). Educational impact of using smart phones for clinical communication on general medicine: More global, less local. Journal of Hospital Medicine, 8(7), 365-372. 